FOUNDATIONS OF SOCIAL ADMINISTRATION 
New books of related interest from Macmillan

The Nature of Social Work

Zofia T. Butrym

The Economics of Social Problems

Julian Le Grand and Ray Robinson 


\title{
Foundations of \\ Social Administration
}

\author{
Edited by \\ Helmuth Heisler \\ Dean of the Faculty of Social Science \\ Lanchester Polytechnic, Coventry
}

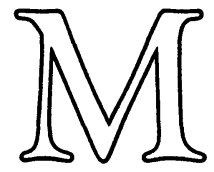


(C) Helmuth Heisler, John Carrier, Bleddyn Davies, Neil Fraser, Howard Jones, Peter Kaim-Caudle, Ian Kendall, Thomas McPherson, Della Adam Nevitt, Muriel Nissel, Barbara Rodgers, J. D. Stewart, George F. Thomason 1977

Softcover reprint of the hardcover 1st edition 1977 978-0-333-18647-3

All rights reserved. No part of this publication may be reproduced or transmitted, in any form or by any means, without permission.

First published 1977 by

THE MACMILLAN PRESS LTD

London and Basingstoke

Associated companies in New York Dublin

Melbourne Johannesburg and Delhi

ISBN 978-0-333-18648-0 ISBN 978-1-349-86159-0 (eBook)

DOI 10.1007/978-1-349-86159-0

\author{
Typeset by \\ SANTYPE (COLDTYPE DIVISION) \\ Salisbury, Wiltshire
}

This book is sold subject to the standard conditions of the Net Book Agreement.

The paperback edition of this book is sold subject to the condition that it shall not, by way of trade or otherwise, be lent, re-sold, hired out, or otherwise circulated without the publisher's prior consent in any form of binding or cover other than that in which it is published and without a similar condition including this condition being imposed on the subsequent purchaser. 


\section{Contents}

Preface ix

1 Dimensions of Social Administration 1 HELMUTH HEISLER

2 Social Administration as Social Science 25 JOHN CARRIER and IAN KENDALL

3 Responsibility and Justice 33 THOMAS McPHERSON

4 Value Choices in Social Administration 46 HOWARD JONES

5 Government, Data and Social Change 57 MURIEL NISSEL

6 Inequality

PETER KAIM-CAUDLE

7 Social Capital 98

NEIL FRASER

8 Demand and Need 113

DELLA ADAM NEVITT

9 Needs and Outputs $\quad 129$

BLEDDYN DAVIES

10 Cohesion or Disjunction in the Planning of Public Policy? 163

J. D. STEWART

11 The Organisation of Professional Work in the Social

Services

GEORGE F. THOMASON

12 Comparative Studies in Social Policy and Administration 196

BARBARA RODGERS

List of Contributors

Notes and References $\quad 225$

Index 
Knowledge begins with practice, and theoretical knowledge which is acquired through practice must then return to practice.

$$
\text { MAO TSE-TUNG }
$$




\section{Preface}

Rooted in the anti-rationalism and then the anti-industrialism of the nineteenth century, in the twentieth century the social-welfare outlook has been a major propellant of the growth of public activity in Britain. Expressed as a percentage of gross domestic product this was 10 per cent at the turn of this century, 50 per cent in 1972, and then public expenditure jumped to 60 per cent in 1975. Much of this has been at the expense of a quarter of a century's under-investment in British industry which, if permitted to continue, will lead to zero or minus growth in the gross domestic product. Even so the supply of a certain level of welfare is necessary for economic production. Thus some of this public activity helps the economy. In view of this growth in welfare it is remarkable that, compared to the other social sciences, so little has been spent on social administration. Although it is a recognised subject it has failed to generate appreciable intellectual interest because it has not yet developed into a discipline. This collection of essays is a reflection of a stirring to establish a discipline by paying attention to positivist as well as the long-standing normative considerations of social administration - in truth, the two are inseparable in any social science.

The book can be divided into three parts. The first of these recognises that every subject has its own peculiarities and distinctiveness which influences the reputation and status it is accorded among academic subjects. Hence in this book about foundations it is sensible to begin by consideration of the traits of social administration - primarily the matter of Chapters 1 to 4 . The phenomena of social conditions, problems and consequential policies provide the genesis for our subject and so are reviewed from a contemporary standpoint in the second part, which covers Chapters 5 to 7. Certain conditions only are defined as social problems which merit organised help and these chapters consider the more critical conditions and policies intended to cope with them. Three of the several ways in which the handling of adverse social conditions can be studied are identified in the final part of the book which spans Chapters 8 to 12 . The traits of social administration permeate the middle and final parts of this book, and both the study of social problems and policies and the specialist 
study of aspects of the understanding and handling of problems reveal the character of social administration. Approaches such as those described in the final part of the book are human as well as analytical responses to the complexity of problems and measures and are ways in which the social administrator acquires expertise and status.

The character of social administration is revealed by the coexistence of its two versions. The older of these sees it in terms of a technical parasite (Chapter 2) or an academic flea living off other subjects (Chapter 4). This version of social administration confined the subject to multidisciplinary studies of the social services, and therefore established its boundaries as those defined by the convenience of public administration and ostensible social legislation. According to this version social administration as a subject does not have boundaries and matter peculiar to itself.

The evolving version of social administration incorporates some of the traits of that which confines the subject to the study of social services. The salient traits of the evolving version will be capitulated under the labels of frontiers, functions, capitalism, social-science theory and a commitment to an open society. It is appropriate when considering the extent of social administration to think of boundaries when the subject is confined to social services which are clearly demarcated by legal and administrative arrangements as in Britain. But this is a restrictive and inaccurate way of thinking about the extent of the subject universally when, for instance, one is dealing with air traffic and noise abatement because of their effects upon living conditions. This is a 'frontier' of our subject, a marginal area inhabited by different categories of persons and phenomena, rather than a boundary. The concept of 'function' is related to the desirability of using the concept of a frontier. As society changes there is no telling what new social problems will be unveiled, and as the social administrator is interested in their solution it is impossible to forecast all the directions in which his attention will be directed. Many social problems will have the objective consequences of solution by means and agencies not commonly regarded as social services and so the logical concomitant of this functional interest is the no-man's land of the frontier. This may be illustrated by reference to Zambia when it was hatching a development plan during the Second World War. The great social problem of the country was the poverty of the peasantry arising from their agriculture and to improve this was seen to be the key to social development. Public aid was to be supplied specifically for this purpose and in the national accounts this was listed under the heading of 'social services'. All kinds of do-gooders as well as agricultural specialists were involved in this welfare frontier - difficult to contemplate through the blinkers of Britain's social-services boundaries. 
Three further aspects of the concept of function require comment. It is argued that social administration could grow as a social science and achieve disciplinary status with a distinctive outlook if it were directed to the allocation of scarce resources to alleviate social problems (Chapter 2). The decision-making involved in this must take account of the beneficial objective consequences for society, that is functions, supposed to result from resource allocations. These are manifest welfare functions that are intended and welcome and latent welfare functions that are unanticipated and also welcome (Chapters 9 and 12). The essence of the contention is that resource allocation is the distinctive purpose of social administration. Tensions created by the persistence of unattended social problems weaken the cohesion of society and this leads to a concept which parallels that of the intended welfare function. This is the possibility that the unintended welfare function of public resource allocation may be better social cohesion (Chapter 1). But the unintended consequences of social administration, called outcomes, are not all desirable. Thus a third concept of latent welfare dysfunction, which arises when more harm than good results from resource allocation (Chapter 8), is required.

The two attitudes to capitalism revealed in this book are typical of social administration. Resources should be redistributed by the state, it is believed, for the benefit of those citizens who, through no fault of their own, become ill, unemployed, destitute and without shelter because they cannot make adequate provision for their own protection due to the vagaries of a capitalist economy. Hence there arises an interest in mediating the unfettered forces of capitalism. More positively there is the opinion that capitalism should be taxed somehow to raise the levels of living for all citizens. Thus a wariness about capitalism characterises many social administrators, some of whom of late, under the influence of the current recession, are revising this attitude. There is a growing understanding that capitalism is not an inexhaustible source of wealth for redistribution after taxation. Capitalism as well as the poor seems to be in need of help and a little more protection than in the past (Chapters 7 and 8 ). These observations serve to exemplify the functional-frontier nature of the evolving version of social administration.

Social administration has emerged as an empirical study whose outlook has been fashioned by social philosophy more than by social-science theory. There is a large chink in the armoury of social administration as a result, interposed between social philosophy and the assumed understanding of actual conditions. To an extent this incomplete outlook has confined social administration to the boundaries of the social services as defined by law and administrative convenience. Tunnel vision results from this. The restraints on resource 
allocation imposed by a political culture or the identification of the wrong phenomena as facts to which resource allocation should respond can only be overcome with the aid of explicit social-science theory (Chapter 1). In connection with the economy and the function of welfare, the contrary interpretations of how to handle inflation, exposed by Keynesians and monetarists, testify to the elusiveness of facts and the necessity of establishing them with the aid of theoretical perspectives. Hence the exploration of welfare frontiers cannot be undertaken without reference to a more adequate repertoire of social-science theory.

A commitment to an open society is an outstanding trait of social administrators. When their reasoning and pleading are blocked by the vested interests which do much to influence the ways in which social problems are dealt with (Chapter 4), their belief in all that belongs to an open society sustains their effort. To a degree moral values, particularly the ascendancy or otherwise of one or other of the important interpretations of justice, contribute to this commitment. There is some choice between the high valuation of liberty of the individual and groups, which is the liberal point of view, and the contrasting high valuation placed on the satisfaction of human needs, the socialist point of view. The dilemma is that liberties may be sacrificed if all that concerns society is the achievement of satisfaction by meeting human needs. A realistic view of justice may involve both the protection of basic liberties and the achievement of benefits by the worst off in society (Chapter 3) and to the extent that this is the view of society also, and it is (Chapter 5), this will temper the importance attached to satisfying human needs irrespective of the cost to human liberty. During a Labour administration, seemingly at the beck and call of the trade-union movement, it is unsurprising that the justice of meeting human needs, the redistribution of the national income by recognition of the rights of the least advantaged to be made as well off as possible, should be the morality which is ascending. But even so this is constrained by the grip of vested interests, which by seeking to ensure the continuance of certain advantages for some groups prevent improvement of the position of others. Are these interests so powerful as to freeze the social order and prevent progress from within? The evidence is encouraging. Change can be generated from within because scope for voluntary action, in defiance of vested interests, is inherent in our open society. Such voluntary action is often in response to the investigative procedures and reports of social administrators and to the extent that this is so they help to provoke the open mind - a precondition for material progress (Chapter 4).

The connections between the state of society and policies for the provision of social services, which now employ two million people, is 
the focus of Chapters 5 to 7 . Social policies are responses to political pressures, which in turn are reactions to social conditions, and in order to appreciate why policies are made and whether they are effective, therefore, three kinds of information are required: knowledge of present conditions, the changes taking place within them and the reasons for these changes. Chapter 5 describes the first two kinds of knowledge about conditions in Britain, including the economic changes which have raised material levels of living, changes in technology which have increased our sensitivity to the predicament of others, organisational changes which have swelled the public service and have added to the power of important groups such as trade unions, and not least the demographic changes which profoundly influence the size of the labour force and economic growth. Knowledge of the economic inequalities brought about by such trends has been of particular interest in the shaping of social policies and forms the subject of Chapter 6, which notes and analyses three categories of economic differences. Here, by the way, it is observed that differences are smaller in income than in wealth. Differences of life styles are reviewed also as are other differences related to work, residence and people's needs.

Social policies by the state are not evolved in response to all trends and conditions. Pressure groups, by identifying only some of these problems, limit those which are subject to policies. The recent increases in social affluence constitute a baseline against which achievement and under-achievement can be assessed and new goals set (Chapter 5). In view of the inclination for social aspirations to rise faster than recordable progress, the appreciable gains which have been recorded should alert us to the possibility of demand for more progress and greater frustration and tension as meagre resources and organisational shortcomings result in measurable under-achievement. Britain's organisational shortcomings, which impede material social progress, arise from its political culture which leads to the laudable search by the state for consensus over so many vital issues. Unfortunately this involves the sharing of power with many groups of people just at the time when, to attain the ever-rising goals of our galloping aspirations, the state should be centralising its power to provide the drive to modernise the country (Chapter 1).

Progress to many entails satisfying the needs of economically disadvantaged groups and the effect of this on economic activity should not be overlooked. This leads to the subject of economic inequalities and the perpetual dispute about the extent to which they should be diminished. Besides the ethical arguments for the reduction of such inequalities (Chapter 3), there is a long-standing concern in Britain that extreme economic inequalities may become the source of deep dispute such as might lead to the overthrow of democracy. On the economic 
front they may inhibit the co-operation of the advantaged and disadvantaged with adverse effect on industrial productivity. Opinions on matters such as these form some of the background for social policies aimed at the redistribution of wealth by means of income maintenance, health and educational provision. In so far as these policies are directed at preventing economic inequalities, they are hampered by uncertainty about their extent, manifestation and origin (Chapter 6).

Social capital also affects progress. There are many projects which are too costly for an individual producer to provide for himself and yet must be supplied by the state without direct charge to him if economic productivity is to be raised. In this connection, the backwardness of the British economy and the question of how social policies affecting the labour market can help it to recover are of recent interest. While industry opposes such policies as would increase its costs at the expense of its profits, it is as well aware as government that certain social policies catering for health, social security and regional needs often may be of positive assistance to the raising of productivity and profits. Neither individual workers nor industries on their own can afford expensive schemes for industrial training. This and decisions about industrial location to utilise idle pockets of localised resources therefore require the intervention of the state. But exactly what and how much should be done requires consideration of what we know about the impact of social policies (Chapter 7).

The supply, organisation and comparison of social services are the popular approaches to social administration discussed in Chapters 8 to 12. Social administration has tended to ignore the effects on the economy of expenditure on the social services and a lack of conceptual clarity has clouded studies of how best to deploy whatever limited resources are set aside for these services. Thus Chapters 8 and 9 contend that the supply of social services is susceptible to economic analysis and that it is vital that an economic approach should be used to help ensure that the economy retains its productive capacity, which may be starved of funds by the social services, and that the scarce resources available for the social services are used wisely. Without a sound economy public resources are unavailable to satisfy the needs of citizens which are beyond their own means, and as the totality of needs if simply summed far exceeds these resources it is essential that they should be used to the best advantage. Hence a certain rationing of provision by the use of prices and measures of quantities assists the identification of priorities, needs to be met and contributes to the assessment of the implications of social-service expenditure for economic activity.

One may speculate about the future effects of the current recession with its low economic growth and high unemployment and wonder 
whether this will dampen aspirations and make people more content with their lot. This implies that aspirations and progress, expressed as needs, may vary from situation to situation and that Marx's dictum of 1875 , 'to each according to his needs', should be construed as relative to the state of society. The study of need, reflecting this dictum, is the accumulation of statistical data about needs for goods and services wanted by arbitrarily chosen groups of consumers who may be too poor to purchase these goods and services. Often such definitions of needs are accompanied by suggestions that they should be catered for at the expense of other needs for which consumers can pay and which generate industry and trade. Thus the social administrator is called upon to make judgements about two kinds of demand: one is the effective demand of the private consumer, which has a direct effect on economic productivity; and the other is social demand, which refers to the exchange of public funds for resources for the social services. It is contended that a rather more rational resource disposition in the public sector is achieved by means of the economic approach to social demand than is possible by persisting with the high valuation of intangibles which is intrinsic in the needology approach to social administration which has held sway until now (Chapter 8).

Moral and social valuations figure large in the identification of human needs in empirical social studies, whereas economists use need in connection with opportunity cost. In this sense it is the recognition that in a situation of scarcity the welfare benefit of providing a given service with these resources will be the consequential cost of not providing some other defined services. Accordingly the value of a unit of social security may be defined as the unit amount of housing which must be forgone in order to create it. To the economist need and social demand are aspects of the same notion: the power of the public sector to commit resources from society for social services and the decision about what quantities of these resources should be directed to each social service. Behind this view of need is the determination of objectives and the order in which they should be realised if resources will not stretch far enough to achieve all of them. This leads to the commitment of different quantities of resources to each objective and its concomitant services. But the allocation of resources to a particular social-service objective provides no certainty that the objective will be achieved. There is an output implication in every way in which given crude resource inputs may be combined and transformed supposedly with the same service objective. For this reason the study of outputs must accompany the economic study of need in order to plan the optimisation of resource output and the achievement of original need objectives. This leads the social administrator with an economic outlook to search for valid measures of need and output to guide 
resource allocation and thus improve the efficiency of social-service provision. Tunnel vision is the usual determinant of resource-allocation decisions, it fails to optimise welfare, and cost-benefit analysis should be put in its place (Chapter 9).

The supply of social services and the attainment of their objectives depend on organisations and the men and women who staff them. Although a need may be identified and adequate resources allocated to ameliorate it, the need may not be met because something is wrong with the responsible organisation or staff. Due to this and the increasing concentration of control, continual reorganisation and more compliance of operational units to their governing bodies mark the social services. Effort to increase such control seems to make more comprehensive planning possible. It is hoped that as a result there will be fewer failures in attaining objectives, but this is a chimera because all relevant relationships cannot be encompassed in plans and the organisations to execute them. This implies that gaps or disjunctions in organisations are as usual as under-achievement, which derives from the tendency for organisations to be built to cope with existing rather than emerging needs. The normal response of organisations to disjunctions and shortcomings is to investigate their position against the perspective of what is known already. This certainly helps organisations to react more speedily and surely to minimise difficulties as they present themselves. But there may be a limit to which organisations can be so adapted and they may in time become obsolete due to the magnitude and nature of needs which will arise in the future. To avoid this, and the futile quest for comprehensive planning, organisations should try to construct imaginative futures which take into account needs barely sensed at present. Organisations are better able to determine if instead of mere adaptation they require restructuring once these projected needs are sensed (Chapter 10).

Scarce means in relation to the growing scale of needs in the social services and the tendency for bureaucratic decision-making bodies to seek to increase their power, at the expense of operational units and staff by limiting their discretion, pose increasing problems for those staff of social services who try to cultivate a professional outlook and behaviour. For instance, whereas central bodies in local government with corporate management perspectives are primarily concerned with efficiency, their professional employees are more concerned with questions of effectiveness. Such perspectives are not wholly compatible. There is a school of thought which believes that society is becoming increasingly bureaucratised, which in turn implies that efficiency considerations must increasingly govern the work of operational units and professionals. But there is scope for the professional outlook to survive in influence, indeed the effective discharge of the social-service 
mission will depend upon this. The improvement of links between bureaucrats and professionals so that the latter can more adequately inject their outlook into corporate decision-making bodies is vital to this, as is the understanding of bureaucrats in these bodies that professional tasks can be performed only in comparative isolation and by the use of discretion by professionally minded operatives. New ways of focusing the opinions of professionals are a countervailing force to the diminution of effectiveness logically inherent in the present operation of local authority corporate management. Some bureaucratic rules are essential if anarchy in professional work is to be avoided, but too many rules may actually prevent the discharge of professional work. Such issues exist within Seebohm social-service departments, and adaptation of the ways in which the professional task and client need should be handled so as to maintain the effectiveness of the socialservice mission is necessary (Chapter 11).

The comparative study of social administration is the last approach discussed in this book. Understanding and knowledge of a particular form of social provision in a single country might be deepened when this is compared with similar provision in another country and this may improve the efficiency and effectiveness of further provision. Before commenting on recent comparative studies of the personal social services and social work, consideration is given to the methodology that should guide such studies. A major difficulty is to determine exactly what phenomena are being compared and in this matter constructive definitions help to make intelligible, and at the same time check by exact observation the accuracy and nature of the phenomena subject to comparison. One product of such a preliminary is a functional definition of the personal social services. These are the practical supports needed by those who have become dependent upon others creating substitute homes for the homeless, providing friend substitutes when they are needed, and providing the necessary social element in the treatment of deviants. The kinds of organisations and staff involved in discharging these functions will vary according to the country studied. The achievement of a functional definition such as this is that it facilitates the communication between social administrators working in different countries of information which is of potential value to them (Chapter 12).

By means of its accounts of social problems, policies and progress, it is hoped that this book will contribute to further public understanding of welfare provision and its inadequacies. At the same time it attempts to show that social administration is in its youth and as such its future development depends on improvements in its ways of formulating problems. As an academic subject it has suffered somewhat because there has been too much thinking about how to make an immediate 
Xviii

Preface

contribution to policies and administration and too little concern about its intellectual tools. This book shows how this is being recognised and the subject reorientated to illuminate more adequately than hitherto how needs are and should be met. Often this leads social administrators beyond the boundaries of the traditional social services into frontiers which will change as society evolves. To cope with this uncertainty about the empirical extent of their subject social administrators are equipping themselves with more adequate theory and methodology.

H. H. 